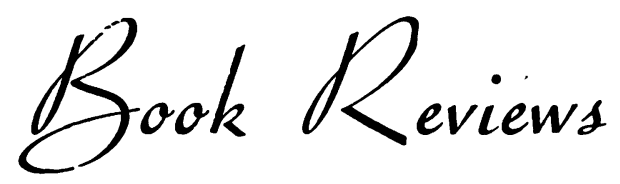

\section{DISEASES OF THE NERVOUS SYSTEM}

By F. M. R. WALShe, M.D., D.Sc., F.R.S. Eighth edition. Pp. xvi +357 , with 58 illustrations. Edinburgh: E. \& S. Livingstone, Ltd. 1955. 24 s.

This continues to be the most useful textbook of neurology available for students and practitioners, its scope having been deliberately restricted to exclude technical details which are more the concern of the specialist.

Its great value lies in the light and shade thrown on the clinical problems which are discussed, and the usual catalogue of detail is avoided. The consultant can still profit from this book, though he may occasionally disagree with the emphasis. The majority of neurologists will feel that the author's treatment of a patient with a sub-arachnoid haemorrhage is too conservative. $\mathrm{He}$ also continues to devote considerable space to the importance of the thoracic inlet syndrome, although it is a relatively insignificant factor in the production of incapacitating discomfort in the arms.

\section{J.N.M.}

\section{MODERN TRENDS IN OPHTHALMOLOGY}

Edited by ArNold SorsBy. Third series. Pp. xiv +346 , with 111 illustrations. London: Butterworth \& Co., Ltd. 1955. 65s.

The present edition of this book which contains roo pages less than its predecessor and less than one half the number of pages of the first edition, is now sold at the increased price of 65 shillings.

The book is divided into six sections comprising of anatomy, physiology and optics; diagnostic procedures; clinical and experimental pathology; clinical aspects; treatment and finally the social aspects of the blind.

As some 50 authors have been responsible for the work it is inevitable that uniformity must be sacrificed. Many of the chapters are excellent, being informative and well written and maintaining the high standard set by the previous editions of this book.

It is unfortunate, however, that many of the chapters have been condensed to such a degree that they are of little interest to the informed reader and of questionable value to the student.
Reference to much recent work has been omitted, especially that concerned with glaucoma, the cornea and retrolental fibroplasia. Despite the fact that Ashton and his co-workers in 1953 elucidated the problem of retrolental fibroplasia, the author of the chapter on that condition states in his final paragraph that 'At present the main aid which can be given is the social adjustment of the patient and his parents.' Whilst it is possible that the compilation of a book of this character demands the early submission of contributions, the responsibility for including out of date material must rest with the editor and in this case, at least, an editorial footnote might have been included to indicate advances which had been published some i 8 months previous to the date of publication of the book.

THE HEALTH OF THE ELDERLY AT HOME By William Hobson, B.Sc., M.D., D.P.H., and John Pemberton, M.D., M.R.C.P. Pp. xvi + 238, with I 2 illustrations. London: Butterworth \& Co., Ltd. 1955. 30s.

The authors are to be congratulated on presenting this handbook as a report on their study of the medical, social and dietary conditions of a group of elderly persons living at home in Sheffield.

Although the number of subjects examined was too small to make the results entirely conclusive, the findings did in fact very closely resemble those found by Dr. Sheldon in his Wolverhampton survey.

The report is short and results from an excellent piece of work very carefully undertaken. It is full of interesting and factual data obtained in a critical way and precisely documented.

The subject is presented well, includes many interesting clinical findings and shows good appreciation of the social implications of many of these.

It is an ideal book for those interested in social medicine and should be available to all medical students.

The authors have kept a good balance between the medical, social and dietary aspects. The routine investigations undertaken give useful data and suggest the need for more detailed studies. The recognition of the importance of social conditions on physical and mental illness is clearly shown and some interesting comparisons are noted. 